\title{
A common Protein Extraction Protocol for Proteomic Analysis: Horse Gram a Case Study
}

\author{
Jyoti Bhardwaj and Sudesh Kumar Yadav \\ Biotechnology Division, CSIR-IHBT, Palampur-176061 (HP), India
}

Received 2012-01-25, Revised 2013-10-25; Accepted 2013-10-28

\begin{abstract}
Three protocols viz. Trichloroacetic Acid (TCA)-acetone, phenol and multi-detergent were compared for the extraction of proteins from horsegram (Macrotyloma uniflorum) which is less studied yet nutritionally and economically very important pulse crop. Almost equal quantity of proteins was extracted by all the three protocols. However, quality of protein from phenol method was superior to that from other protocols. Bands in One-Dimensional (1-D) and Two-Dimensional Electrophoresis (2DE) of phenol protocol were reproducible and better. We report here a modified and common protocol for the extraction of proteins for proteomic analysis. The developed protocol is applicable not only to other economically important leguminous but also non-leguminous crops.
\end{abstract}

Keywords: Trichloroacetic Acid (TCA), Pinch of Bromophenol Blue (PBB), Two-Dimensional Electrophoresis (2-DE), One-Dimensional (1-D), Sodium Dodecyl Sufate (SDS)

\section{INTRODUCTION}

Legumes form the third largest plant family (Dam et al., 2009). These are also among the largest and most diverse families of flowering plants (Brandon et al., 2007). Grain legumes contribute 33\% of daily protein intake of humans (Graham and Vance, 2003). Model legume studies are important for establishing overall legume development (Dam et al., 2009). The most common legume models are peanut, Lotus, Medicago, soybean, scarletrunner bean, common bean, pea and broadbean (Goldberg et al., 1989; Johnson et al., 1994; Coste et al., 2001; Weterings et al., 2001; Weber et al., 2005). But we chose horsegram (Macrotyloma uniflorum) as the study material. Being a pulse legume it is rich in proteins. It is an important yet underexploited legume and is also known as the poor man's pulse. It has been identified as potential food source for the future (Prakash et al., 2008; Kadam and Salunkhe, 1985).

Proteomics is the branch of science dealing with the isolation, identification and characterization of proteins. On the other hand similar field of genomics is on a high tide. Among legumes, in addition to the soybean genome sequence (Jackson et al., 2006) other legume genome sequences are going to be available soon (Broughton et al., 2003; Gepts et al., 2005; Young et al., 2005). Proteomics still requires huge effort. A large number of groups have published protein reference maps for specific Medicago tissues (Lei et al., 2005; Mathesius et al., 2001; Watson et al., 2003; Imin et al., 2004; Gallardo et al., 2003). Still there is no fully characterized proteome equivalent to a fully sequenced genome. Though genomic studies are opening new dimensions every day, but they do not always provide a complete story due to limited correlations in transcript and protein levels (Gygi et al., 1999). Latter could be due to post-translational modifications, proteolysis and protein-protein interactions. The mass spectroscopic analysis, database searching and software for structure prediction allow rapid identification of proteins (Cilia et al., 2009). Thus, proteomics has become a critical complement to genomic data.

Corresponding Author: Sudesh Kumar Yadav, Biotechnology Division, CSIR-IHBT, Palampur-176061 (HP), India Fax: 91-1894-230425 
Proteomics is a fast changing field and new protocols are being established frequently. Still there is a dearth of common protocols for extraction of proteins from variable sources. Since horsegram is an unexplored legume, its proteomic analysis requires special attention. Studies on biochemical parameters, antioxidant enzymes and computational study on miRNAs of horsegram has been already conducted in our lab. In this study, we developed a modified and common protocol using horsegram as a case study plant material. Further, the developed protocol was used to extract proteins from other legume and nonlegume crops.

\section{MATERIALS AND METHODS}

\subsection{Sample}

Seeds were used for extraction of proteins from legumes. The legumes selected besides horsegram (Macrotyloma uniflorum) were rajmah (Phaseolus vulgaris), mah (Vigna mungo), chickpea (Cicer arietinum), masoor (Lens culinaris) and mungbean (Vigna radiata). Among non-legumes rice (Oryza sativa), wheat (Triticum aestivum), bajra (Pennisitum glaucum) and mustard (Brassica juncea) were taken for the study.

\subsection{Protocols}

The protocols are developed following the earlier used protocols (Cilia et al., 2009). The modifications made in the developed protocol are as follows. The first protocol used for extraction of the proteins was using TCA and acetone. The plant tissue $(100 \mathrm{mg})$ was homogenized in $10 \%$ TCA containing $2 \% \beta$ Mercaptoethanol ( $\beta-\mathrm{ME})$ using liquid nitrogen. It was kept overnight for precipitation at $-20^{\circ} \mathrm{C}$. Next day, the mixture was centrifuged at $5000 \mathrm{~g}$ for $30 \mathrm{~min}$ at $4^{\circ} \mathrm{C}$. The supernatant was discarded and precipitates were washed thrice with ice cold acetone. The precipitates were agitated vigorously in between each wash. The precipitates were then air dried till they appeared to be damp but not dried or cracked. These precipitates were dissolved in $1 \mathrm{ml}$ of the modified lysis buffer ( $9 \mathrm{M}$ urea, $2 \mathrm{M}$ thiourea, 1\% DTT and 4\% CHAPS).

The second protocol involved the extraction of proteins using phenol. Plant tissue $(100 \mathrm{mg})$ was homogenized well in the modified phenol extraction buffer (500 mM Tris ( $\mathrm{pH} 7.5$ ), 2\% non-idet P 40 (NP40 ), $2 \% \beta$-ME, $0.7 \mathrm{M}$ sucrose, $0.5 \mathrm{M}$ sodium chloride and protease inhibitor cocktail). To this, equal volume of cold Tris-saturated phenol ( $\mathrm{pH} 7.5$ ) was added. This mixture was shaken vigorously for $30 \mathrm{~min}$ at $4{ }^{\circ} \mathrm{C}$ and then centrifuged at $5000 \mathrm{~g}$ for $30 \mathrm{~min}$ at $4^{\circ} \mathrm{C}$. The upper phenol phase containing the proteins was collected very carefully. Ammonium acetate $(0.1 \mathrm{M})$ was added five times the volume of the phenol phase. Mixed well and kept for precipitation overnight at $20^{\circ} \mathrm{C}$. Next day, the mixture was centrifuged at $5000 \mathrm{~g}$ for $30 \mathrm{~min}$ at $4{ }^{\circ} \mathrm{C}$. The supernatant was discarded and the precipitates were washed twice in methanol and thrice in ice-cold acetone as described for TCAacetone protocol till their dissolution in the same lysis buffer.

For the third protocol, homogenization of $100 \mathrm{mg}$ of tissue was done in the modified multi-detergent extraction buffer $(100 \mathrm{mM}$ dibasic potassium phosphate (pH 7.6), $8 \mathrm{M}$ urea, $1 \%$ tritonX-100, $20 \%$ glycerol, $0.5 \mathrm{M}$ sodium chloride and protease inhibitor cocktail). This was shaken at room temperature for 10-15 min and then centrifuged at $9500 \mathrm{~g}$ for $30 \mathrm{~min}$ at $4{ }^{\circ} \mathrm{C}$. To the supernatant equal volume of $10 \%$ TCA containing $2 \% \beta$-ME was added and kept overnight for precipitation at $-20^{\circ} \mathrm{C}$. Next day, the mixture was centrifuged at $5000 \mathrm{~g}$ for $30 \mathrm{~min}$ at $4^{\circ} \mathrm{C}$. The supernatant was discarded and the precipitates were washed thrice in ice-cold acetone as described for TCA-acetone protocol till their dissolution in the same lysis buffer.

\subsection{Quantification and 1-DE}

The proteins were quantified using Bradford reagent (Bradford, 1976) and samples were analyzed in triplicates. Sodium Dodecyl Sufate (SDS) PAGE (12\%) was used for 1-D electrophoresis analysis. The volume for each sample used was $25 \mu \mathrm{L}^{-1}$. The gels were run at $30 \mathrm{~mA}$ of current per gel in the stacking gel and at $35 \mathrm{~mA}$ in the separating gel. The gels were stained in $\mathrm{CBB}$ and then destained in a solution containing $10 \%$ glacial acetic acid and 30\% methanol.

\subsection{2-DE}

The samples dissolved in lysis buffer were taken such that their concentration reached to 0.1-2.5 $\mu \mathrm{g}$ $\mu \mathrm{L}^{-1}$ for 2-DE. This concentration of the sample was dissolved in rehydration buffer $(8 \mathrm{M}$ urea, $2 \%$ CHAPS, $20 \mathrm{mM}$ DTT and $0.2 \%$ IPG buffer). This buffer was stored in small aliquots as per requirement at $-20^{\circ} \mathrm{C}$. The last two ingredients (DTT and IPG buffer) were added fresh to the rehydration buffer just 
before use. A total of $125 \mu \mathrm{L}$ of rehydration buffer containing the sample was evenly distributed in the rehydration strip holder. The 7cm IPG strip ( $\mathrm{pH}$ 3-10 nonlinear, GE Healthcare, Sweden) was placed on it and this assembly was allowed to rehydrate passively overnight. IEF was conducted in Ettan IPGphor II (GE Healthcare, sigma). Current of $50 \mu \mathrm{A}$ strip as applied. The focusing conditions were: step 1-300 V, step 2$500 \mathrm{~V}$, step 3-1000 V and step 4-5000V. The focused strips were first reduced in equilibration buffer $(6 \mathrm{M}$ urea, $50 \mathrm{mM}$ Tris $\mathrm{pH}(8.8), 30 \%$ glycerol, $2 \%$ SDS and Pinch of Bromophenol Blue (PBB)) containing 50 mg DTT (added just prior to use) for $15 \mathrm{~min}$ on a gel rocker at room temperature. The reduced strips were then alkylated by adding fresh $75 \mathrm{mg}$ Iodoacetamide (IAA) at similar conditions. The reduced and alkylated strips were washed with $1 \times$ SDS buffer. These strips were then loaded onto $12 \%$ SDS PAGE without any stacking gel. This assembly was sealed using $1 \%$ agarose sealing buffer. The gels were run, stained and destained just as for 1-D electrophoresis. The gels were scanned using Imagemaster 2D Platinum (GE Healthcare, Sweden).

\section{RESULTS AND DISCUSSION}

According to the protein yield results, all the three protocols were almost at par with each other (Fig. 2). TCA-acetone and phenol-acetone protocols yielded $15.92 \pm 0.02$ and $15.35 \pm 0.09 \mathrm{mg} \mathrm{g}^{-1} \mathrm{FW}$ protein while multi-detergent protocol yielded $15.07 \pm 0.11 \mathrm{mg} \mathrm{g}^{-1} \mathrm{FW}$ protein. Our results are in agreement to the earlier reported studies (Cilia et al., 2009; He and Wang, 2008). They have also documented the highest protein yield by TCA-acetone protocol. But based on the quality of 1-D and 2-DE analysis phenol method was chosen for extraction of proteins. Many other groups working with extraction of proteins for 2-DE has chosen phenol method directly or with modifications for their analysis (Wang et al., 2006; Cilia et al., 2009; Dam et al., 2009).

\subsection{Phenol-Acetone Protocol was Better Than Other Two Protocols}

The pellets following precipitation from the three extraction protocols had unique characteristics. The precipitants from the TCA-acetone protocol were good in amount and easy to handle. These were off white in color, grainy, little viscous but solublized in lysis buffer moderately giving a turbid solution initially. Earlier also pellets from TCA-acetone protocol have been found to be light brown in color and grainy in nature (Cilia et al., 2009). Homogenizing the sample in $10 \%$ TCA dissolved in acetone was found to almost immediately precipitate proteins. It also allowed interfering substances that dissolved in the acetone to be washed from the precipitated proteins and provided a clean sample for IEF. Although this protocol is effective for some plant tissues, it often results in the co-extraction of polymeric contaminants (Rose et al., 2004). These contaminants precipitate with proteins and cannot be removed by the final washing steps (He and Wang, 2008). The precipitants from the phenol-acetone protocol were whitish in color, flaky, non-viscous, easy to handle and solubilized immediately in the lysis buffer. It has been reported earlier that the protein pellet from phenol extraction is usually white and a yellowish pellet indicates co-precipitation of phenolic compounds. Such pellets have been reported to be easily dissolved in the rehydration buffer. Hence, qualitatively the phenol extraction has been considered to give the cleanest and most soluble pellet (Cilia et al., 2009). Interestingly, another study has reported that non-protein contaminants can be removed using phenol protocol resulting in change in color of the ground powder from brownish to white (He and Wang, 2008). However, the precipitants from the multi-detergent protocol were yellowish in color and very difficult to handle being sticky in nature. These were not easily soluble in lysis buffer. These problems along with lower protein yield makes this protocol unfit according to our studies. It has also been reported earlier that the pellets from multidetergent protocol are dark-brown in color and viscous in nature (Cilia et al., 2009).

After quantification of the proteins achieved by different methods, SDS-PAGE was run to observe the banding pattern (Fig. 3). Samples were run in duplicate to check reproducibility of the three methods. All the methods were reproducible. The TCA-acetone protocol did not give very clear and high intensity bands. The phenol-acetone protocol gave better results. The bands were very sharp and distinct. Similar results have been reported earlier with phenol extraction protocol (Cilia et al., 2009; Wang et al., 2006). Multi-detergent protocol although gave high intensity bands but failed in clarity and sharpness of 1-DE gel-banding pattern. This method has also been reported to be nonreproducible earlier (Cilia et al., 2009). 
J. Bhardwaj and S.K. Yadav / American Journal of Agricultural and Biological Sciences 8 (4): 293-301, 2013

TCA-aceton method

Homogenized (in liq. $\mathrm{N}_{2}$ ) $100 \mathrm{mg}$

Homogenisation tissue in $1 \mathrm{ml}$ of $10 \% \mathrm{TCA}$ in acetone containing $2 \%$ of 2 -mercaptoethanol

(1)

Homogenized (in liq. $\mathrm{N}_{2}$ ) $100 \mathrm{mg}$ tissue in $1 \mathrm{ml}$ of phenol-acetone extraction buffer

Extracted proteins by adding equal volume of Tris-saturated phenol (pH 7.5)

Shaken vigorously for $30 \mathrm{~min}, 4^{\circ} \mathrm{C}$ Centrifuged at $5000 \mathrm{~g}$ for $30 \mathrm{~min}$ at $4^{\circ} \mathrm{C}$

Carefully collect the upper phenol phase. Re-extract (if required)

Added 5 volumes of $0.1 \mathrm{M}$ ammonium acetate in methanol

Kept overnight for precipitation at $-20^{\circ} \mathrm{C}$

Precipitation

Centrifugation

Wash the pellets thrice with icecold acetone. Vigorously disnupt pellets in between each wash
Next day centrifuged at $5000 \mathrm{~g}$ for

$30 \mathrm{~min}$ at $4^{\circ} \mathrm{C}$

Wash the pellets twice with icecold methanol and thrice with icecold acetone. Vigorously disnupt pellets in between each wash

Wash the pellets thrice with icecold acetone. Vigorously disrupt pellets in between each wash

\section{Air dried the pellets \\ $\downarrow$ \\ Store the pellets at $-80^{\circ} \mathrm{C}$ or dissolve in lysis buffer}

Fig. 1. Flowchart of the three protocols used for the extraction of proteins for 2-DE

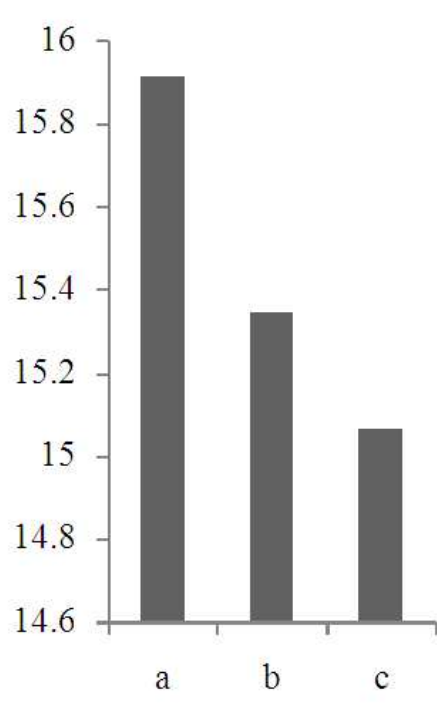

(A)

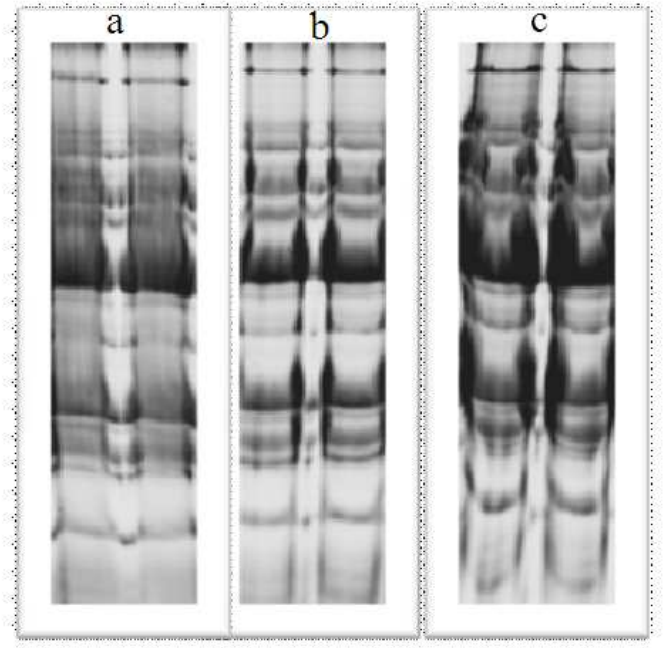

(B)

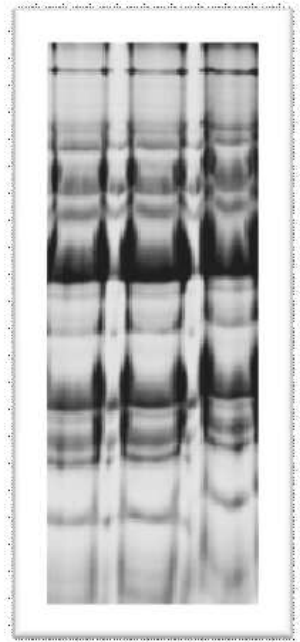

(C)

Fig. 2. Comparison of the extracted protein from horsegram seeds by quantification and 1-DE analysis. (A) Protein yield from three different protocols; (a) TCA-acetone (b) phenol-acetone and (c) multi-detergent. (B) SDS-PAGE analysis of the three protocols. (C) Triplicates of the phenol-acetone protocol 


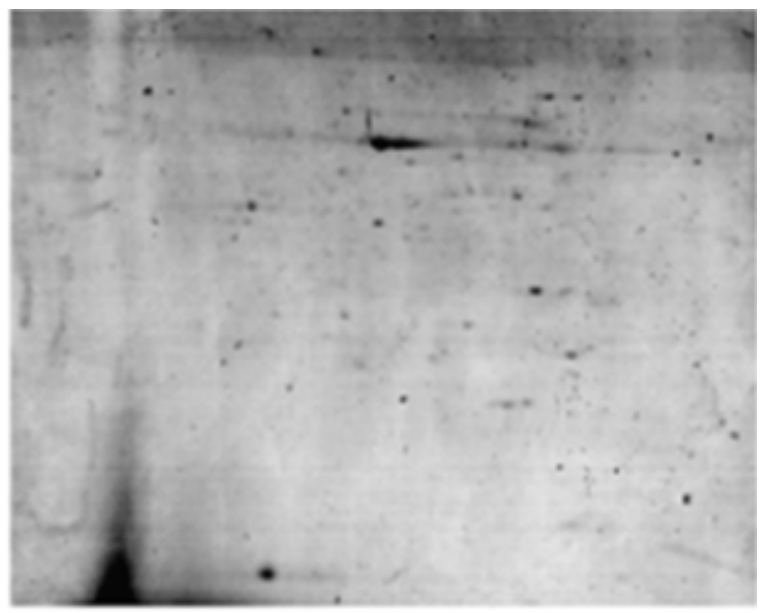

(A)

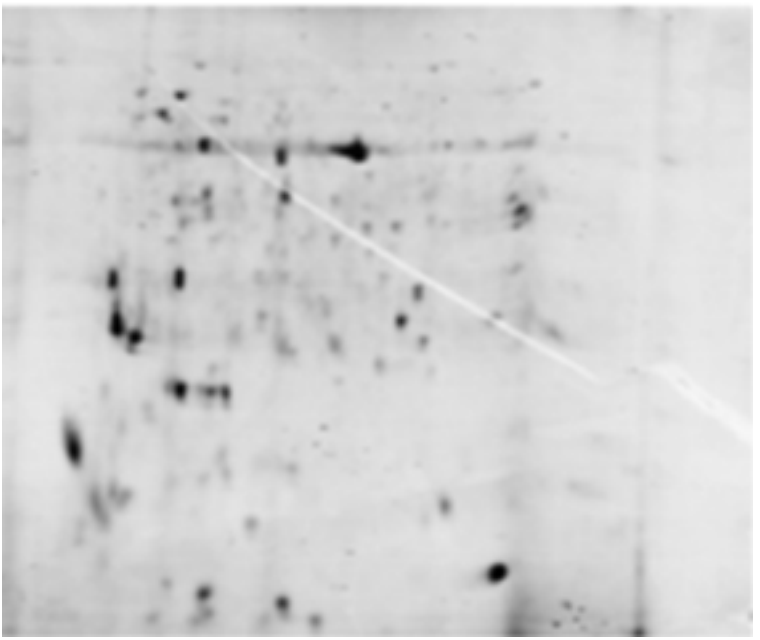

(B)

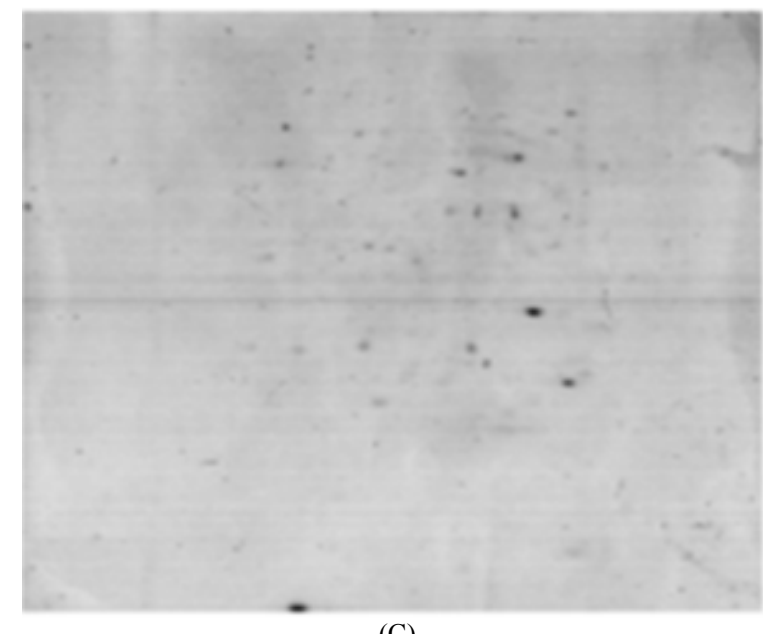

(C)

Fig. 3. Two-dimensional electrophoresis analysis of the three protocols compared for extraction of proteins from horsegram seedlings. (A) TCA-acetone (B) Phenol-acetone and (C) Multi-detergent

After the initial screening at the 1-D electrophoresis level, the quality of proteins were checked on 2-DE (Fig. 3). We observed that the phenol-acetone method gave good and clear spots on the 2-DE gel. The other two protocols gave lesser number of protein spots being difficult to observe. Most of the spots present in the phenol-acetone protocol were either absent or less visible in the 2-DE pattern of other two protocols. The enhanced performance of the phenol-acetone extraction protocol could be due to the fact that contaminants were eliminated more efficiently with the aqueous phase. It has been reported earlier that phenol protocol resulted in better 2-DE quality than TCA-acetone although latter gave higher protein yield (He and Wang, 2008). Taken together, the quantitative, qualitative, 1-D and 2-DE analysis of the protocols tested, we found the phenol-acetone protocol better for extraction of protein from horsegram for 2-DE.

\subsection{Phenol-Acetone Protocol Can be Applied to Both Legumes and Non-Legumes}

Proteins from different legumes and non-legumes were extracted using phenol-acetone protocol and then quantified (Fig. 4). Among legumes the highest protein concentration was shared by rajmah and chickpea $\left(14.25 \pm 0.005 \mathrm{mg} \mathrm{g}^{-1} \mathrm{FW}\right)$, then followed by lentil (14.02 $\left.\pm 0.005 \quad \mathrm{mg} \mathrm{g}^{-1} \mathrm{FW}\right)$, mungbean $\left(13.87 \pm 0.015 \mathrm{mg} \mathrm{g}^{-1} \mathrm{FW}\right)$ and $\mathrm{mah}(13.83 \pm 0.02 \mathrm{mg}$ $\left.\mathrm{g}^{-1} \mathrm{FW}\right)$. Among non-legumes the order was mustard showing the highest concentration $(14.09 \pm 0.045 \mathrm{mg}$ $\left.\mathrm{g}^{-1} \mathrm{FW}\right)$ followed by rice $\left(13.05 \pm 0.01 \mathrm{mg} \mathrm{g}^{-1} \mathrm{FW}\right)$, bajra $\left(12.92 \pm 0.005 \quad \mathrm{mg} \mathrm{g}^{-1} \mathrm{FW}\right)$ and wheat $\left(12.28 \pm 0.07 \mathrm{mg} \mathrm{g}^{-1} \mathrm{FW}\right)$. 


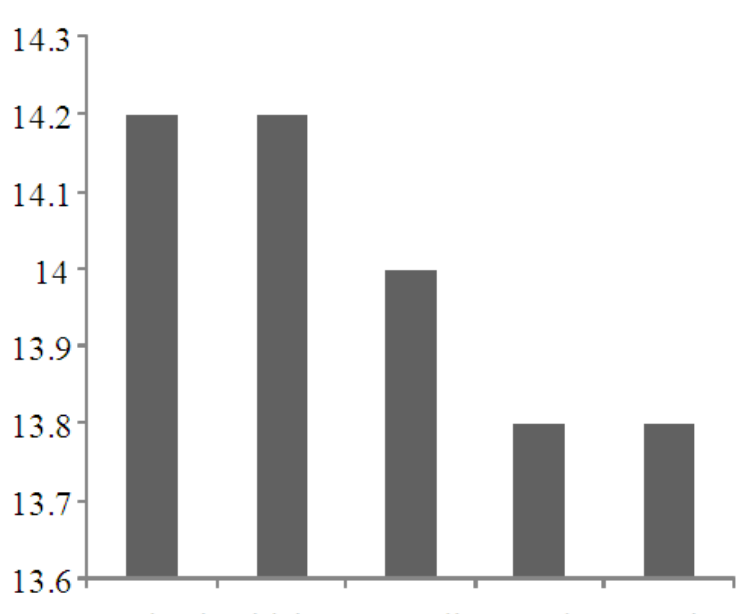

Rajmah Chickpea Lentil Mungbean Mah

(A)

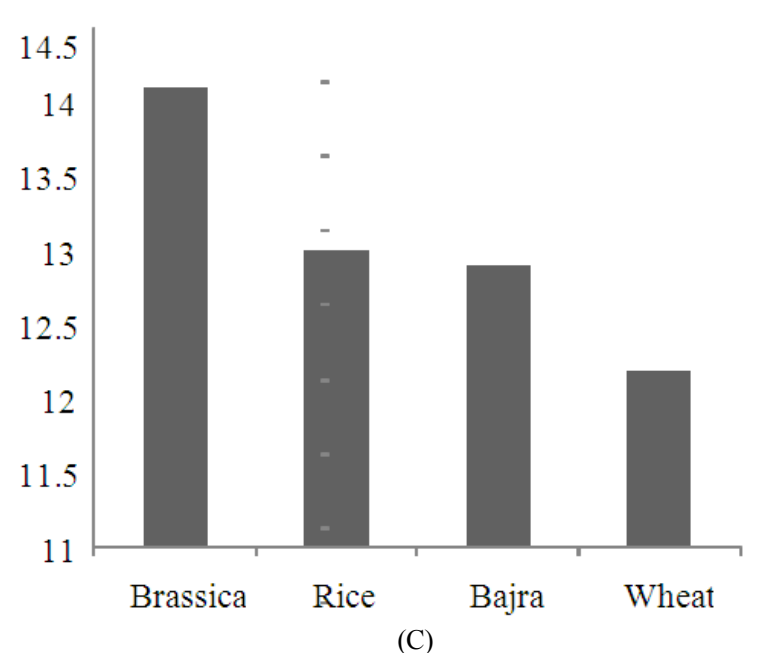

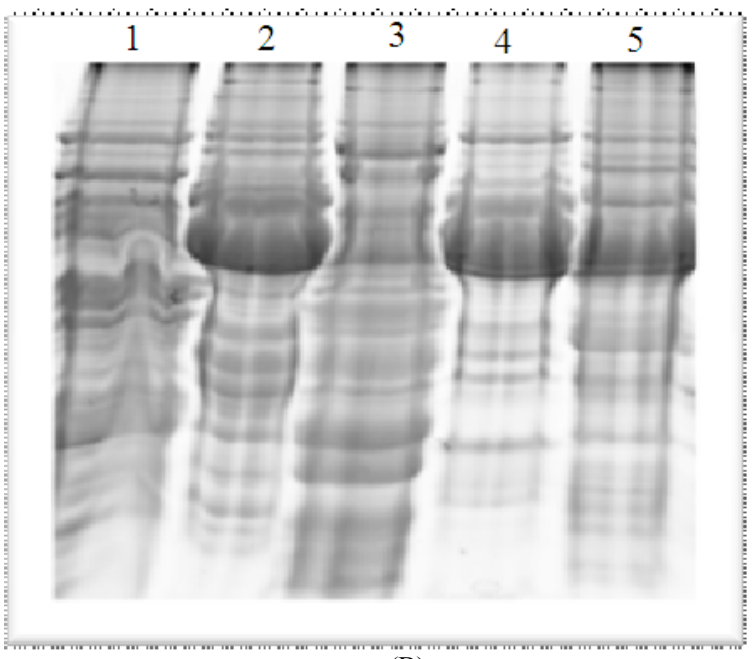

(B)

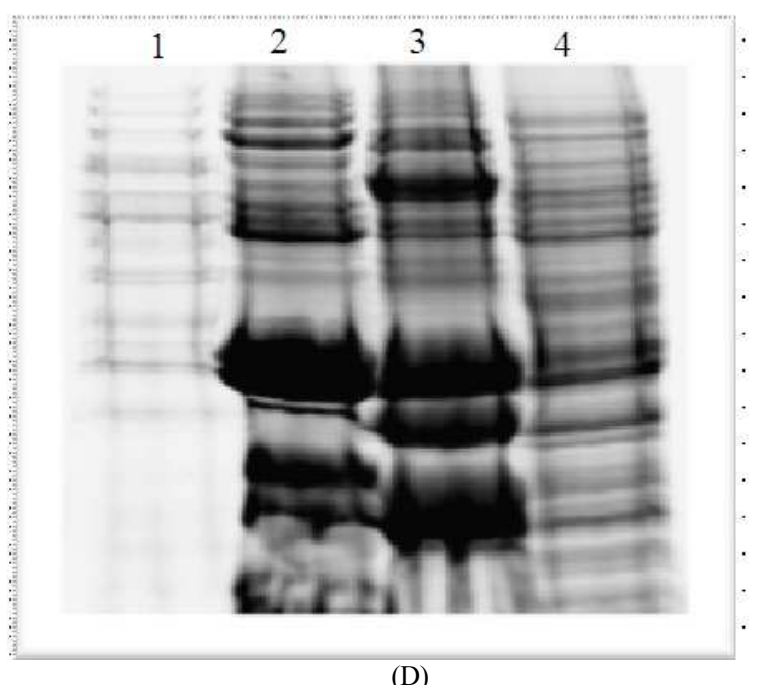

Fig. 4. Extraction of proteins from different legumes and non-legumes using phenol-acetone protocol. Protein yields in legumes (A) and non-legumes (C). SDS-PAGE of proteins from (B) legumes (Lane 1- rajmah, Lane 2- mah, Lane 3- chickpea, Lane 4mungbean and Lane 5- lentil) and (D) non-legumes (Lane 1-wheat, Lane 2-rice, Lane 3-mustard and Lane 4-bajra)

Good banding patterns were observed in 1-D electrophoresis for different legumes and non-legumes (Fig. 4). Among non-legumes, the intensity of bands was less for wheat while rice and mustard showed good bands. Best protein bands among non-legumes were observed for bajra. This protocol extracts good and fairly equal amount of proteins from leguminous as well as non-leguminous samples as is shown by quantification of proteins. Earlier, a protocol based on phenol extraction has been reported to be highly effective for the production of high-quality protein samples from only recalcitrant plant tissues (Wang et al., 2006). Phenol protocol has also been applied for extraction of proteins from different plants. However, there was no quantification data (Cilia et al., 2009; He and Wang, 2008).

\section{CONCLUSION}

Sample preparation is one of the most crucial and problematic step when high-quality resolution of proteins is desired in proteomic analysis (Wang et al., 2006). To deal with these challenges, we tested and compared three protein extraction protocols with modifications: TCA-acetone, phenol and multidetergent (Fig. 1). Earlier also these basic protocols have been compared for samples ranging from insects to recalcitrant plants (Cilia et al., 2009; Wang et al., 
2006; He and Wang, 2008; Barraclough et al., 2004). However, we have standardized a common protocol for protein extraction from legumes and non-legumes. We tried different combinations of chemicals and detergents to modify the extraction and lysis buffers. Finally, we decided not to make any changes in the first protocol. But the extraction buffers for second and third protocol were modified for better extraction as is evident by protein yield. The reason behind this could be that TCA-acetone protocol is simpler than phenol protocol. The number of steps in the phenol or multi-detergent protocol might have caused some loss of proteins quantitatively. The lysis buffer common to all three protocols was also modified for better solubilization. In phenol protocol the extraction buffer was modified to suit extraction of proteins from plant. Instead of potassium chloride we used sodium chloride as latter is more commonly used for extraction of proteins from plant sources. Polyvinylpolypyrrolidone (PVPP), PMSF and EDTA were not used. We used NP-40 and protease inhibitor cocktail in the phenol extraction buffer. One washing step with acetone was increased for the phenol protocol. Therefore, we call our method phenolacetone protocol. In multi-detergent extraction buffer, $8 \mathrm{M}$ urea was used instead of $7 \mathrm{M}$ urea. Amidosulfobetaine-14 and $1 \%$ dodecyl maltoside were omitted. We used sodium chloride and tritonX100. CHAPS and thiourea were omitted from the extraction buffer. In the lysis buffer, $9 \mathrm{M}$ urea was used instead of $7 \mathrm{M}$ and $1 \%$ DTT was added to enhance solubility besides the usual components.

Earlier also a combination of TCA/acetone and phenol protocol has been shown to provide enhanced 2-DE based proteomic analysis of most plant tissues (Cilia et al., 2009; Wang et al., 2006). Protein extraction from plant tissues is challenging due to relatively low protein concentration and high levels of polysaccharides, polyphenols, pigments and lipids. These all can contribute to horizontal or vertical streaking, proteolytic degradation and artificial migrations on 2-DE gels (Carpentier et al., 2005). Protein extraction methods to obtain well-resolved 2DE maps from different samples have been reported previously (Wang et al., 2006; Charmont et al., 2005; Mijnsbrugge et al., 2000). Methanol is often used to extract polyphenolic compounds. However, in combination with ammonium acetate it facilitates the extraction of proteins by phenol at an increased $\mathrm{pH}$ (Wang et al., 2006). It is known that exposure to low $\mathrm{pH}$ may lead to protein degradation or modifications, therefore buffers were kept within $\mathrm{pH}$ 7-8. Earlier also in a study on Aloe vera, a lysis buffer with $\mathrm{pH}$ around or above 8 for all three methods has been used resulting in better performance at 2-DE (Wang et al., 2006; He and Wang, 2008). The strips chosen (pH 310) have allowed a good resolution of the legume proteins that mostly range in $\mathrm{pI}$ from 4-7. Despite the fact that phenol-acetone protocol involves more number of steps, its reproducibility, good protein yield and high intensity bands/spots makes it a better protocol.

\subsection{Funding Information}

This study was supported by Department of Science and Technology, GOI in the form of project (SR/WOS-A/LS-243/2009) granted to JB under WSS (WOS-A) scheme.

\section{ACKNOWLEDGEMENT}

Researchers are full of gratitude towards the Director, CSIR-IHBT for his support and facility. Council of Scientific and Industrial Research, GOI is duly acknowledged for financial support in the laboratory.

\section{REFERENCES}

Barraclough, D., D.M. Obenland, W. Laing and T. Carrol, 2004. A general method for two-dimensional protein electrophoresis of fruit samples. Postharvest Biol. Tecnol., 32: 175-181. DOI: 10.1016/j.postharvbio.2003.11.002

Bradford, M.M., 1976. A rapid and sensitive method for the quantitation of microgram quantities of protein utilizing the principle of protein-dye binding. Anal. Biochem., 72: 248-254. DOI: 10.1016/00032697(76)90527-3

Brandon, H.L., J.A. Wagmaister, T. Kawashima, A.Q. Bui and J.J. Harada et al., 2007. Using genomics to study legume seed development. Plant Physiol., 144: 562-574. DOI: 10.1104/pp.107.100362

Broughton, W.J., G. Hernandez, M. Blair, S. Beebe and P. Gepts et al., 2003. Beans (Phaseolus spp.)-model food legumes. Plant Soil, 252: 55-128. DOI: 10.1023/A:1024146710611

Carpentier, S.C., E. Witters, K. Laukens, P. Deckers and R. Swennen et al., 2005. Preparation of protein extracts from recalcitrant plant tissues: An evaluation of different methods for twodimensional gel electrophoresis analysis. Proteomics, 5: 2497-2507. DOI: 10.1002/pmic. 200401222 
Charmont, S., E. Jamet, R. Pont-Lezica and H. Canut, 2005. Proteomic analysis of secreted proteins from Arabidopsis thaliana seedlings: Improved recovery following removal of phenolic compounds. Phytochem, 66: 453-461. DOI: 10.1016/j.phytochem.2004.12.013

Cilia, M., T. Fish, X. Yang, M. Mclaughlin and T.W. Thannhauser et al., 2009. A comparison of protein extraction methods suitable for gel-based proteomic studies of aphid proteins. J. Biomol. Tech., 20: 201215. PMID: 19721822

Coste, F., B. Ney and Y. Crozat, 2001. Seed development and seed physiological quality of field grown beans (Phaseolus vulgaris L.). Seed Sci. Technol., 29: 121-136.

Dam, S., S.B. Laursen, J.H. Ornfelt, B. Jochimsen and H.H. Stærfeldt et al., 2009. The proteome of seed development in the model legume Lotus japonicas. Plant Physiol., 149: 1325-1340. DOI: 10.1104/pp.108.133405

Gallardo, K., C.L. Signor, J. Vandekerckhove, R.D. Thompson and J. Burstin, 2003. Proteomics of Medicago truncatula seed development establishes the time frame of diverse metabolic processes related to reserve accumulation. Plant Physiol., 133: 664-682. DOI: 10.1104/pp.103.025254

Gepts, P., W.D. Beavis, E.C. Brummer, R.C. Shoemaker and H.T. Stalker et al., 2005. Legumes as a model plant family. Genomics for food and feed report of the cross-legume advances through genomics Conference. Plant Physiol., 137: 1228-1235. DOI: 10.1104/pp.105.060871

Goldberg, R.B., S.J. Barker and L. Perez-Grau, 1989. Regulation of gene expression during plant embryogenesis. Cell, 56: 149-160. PMID: 2643470

Graham, P.H. and C.P. Vance, 2003. Legumes: Importance and constraints to greater use. Plant Physiol., 131: 872-877. DOI: 10.1104/pp.017004

Gygi, S.P., Y. Rochon, B.R. Franza and R. Aebersold, 1999. Correlation between protein and mRNA abundance in yeast. Mol. Cell Biol., 19: 1720-1730. PMID: 10022859

He, C.F. and Y.M. Wang, 2008. Protein extraction from leaves of Aloe vera L., a succulent and recalcitrant plant, for proteomic analysis. Plant Mol. Biol. Rep., 26: 292-300. DOI: 10.1007/s11105-008-0040-9

Imin, N., F.D. Jong, U. Mathesius, G.V. Noorden and N.A. Saeed et al., 2004. Proteome reference maps of Medicago truncatula embryogenic cell cultures generated from single protoplasts. Proteomics, 4: 1883-1896. DOI: 10.1002/pmic.200300803
Jackson, S.A., D. Rokhsar, G. Stacey, R.C. Shoemaker and J. Schmutz et al., 2006. Toward a reference sequence of the soybean genome: A multiagency effort. Crop Sci., 46: S55-S61. DOI: 10.2135/cropsci2006.08.0514tpg

Johnson, S., C.M. Liu, C.L. Hedley and T.L. Wang, 1994. An analysis of seed development in Pisum sativum XVIII. The isolation of mutants defective in embryo development. J. Exp. Bot., 45: 1503-1511. DOI: $10.1093 / \mathrm{jxb} / 45.11 .1503$

Kadam, S.S. and D.K. Salunkhe, 1985. Nutritional composition, processing and utilization of horse gram and moth bean. Crit. Rev. Food Sci. Nutr., 22: 1-26. PMID: 3899515

Lei, Z., A.M. Elmer, B.S. Watson, R.A. Dixon and P.J. Mendes et al., 2005. A two-dimensional electrophoresis proteomic reference map and systematic identification of 1367 proteins from a cell suspension culture of the model legume Medicago truncatula. Mol. Cell Proteom., 4: 1812-1825. DOI: 10.1074/mcp.D500005-MCP200

Mathesius, U., G. Keijzers, S.H. Natera, J.J. Weinman and M.A. Djordjevic et al., 2001. Establishment of a root proteome reference map for the model legume Medicago truncatula using the expressed sequence tag database for peptide mass fingerprinting. Proteomics, 1: 1424-1440. DOI: 10.1002/1615861200111

Mijnsbrugge, K.V., H. Meyermans, M. Van Montagu, G. Bauw and W. Boerjan, 2000. Wood formation in poplar: Identification, characterization and seasonal variation of xylem proteins. Planta, 210: 589-598. DOI: $10.1007 / \mathrm{s} 004250050048$.

Prakash, B.G., M.B. Guled and A.M. Bhosale, 2008. Identification of suitable horsegram varieties for northern dry zone of Karnataka. Karnataka. J. Agric. Sci., 21: 343-345.

Rose, J.K., S. Bashir, J.J. Giovannoni, M.M. Jahn and R.S. Saravanan, 2004. Tackling the plant proteome: Practical approaches, hurdles and experimental tools. Plant J., 39: 715-733. DOI: 10.1111/j.1365313X.2004.02182.X

Wang, W., R. Vignani, M. Scali and M. Cresti, 2006. A universal and rapid protocol for protein extraction from recalcitrant plant tissues for proteomic analysis. Electrophoresis, 27: 2782-2786. DOI: 10.1002/elps.200500722

Watson, B.S., V.S. Asirvatham, L. Wang and L.W. Sumner, 2003. Mapping the proteome of barrel medic (Medicago truncatula). Plant Physiol., 131: 1104-1123. DOI: 10.1104/PP.102.019034 
Weber, H., L. Borisjuk and U. Wobus, 2005. Molecular physiology of legume seed development. Ann. Rev. Plant Biol., 56: 253-279. DOI: 10.1146/annurev.arplant.56.032604.144201

Weterings, K., N.R. Apuya, Y. Bi, R.L. Fischer and J.J. Harada et al., 2001. Regional localization of suspensor mRNAs during early embryo development. Plant Cell, 13: 2409-2425. DOI: 10. 1105/tpc.010326
Young, N.D., S.B. Cannon, S. Sato, D. Kim and D.R. Cook et al., 2005. Sequencing the genespaces of Medicago truncatula and Lotus japonicus. Plant Physiol., 137: 1174-1181. DOI: 10.1104/pp.104.057034 